Behavior and Social Issues, 21, 5-25 (2012). (C) Angela Sanguinetti. Readers of this article may copy it without the copyright owner's permission, if the author and publisher are acknowledged in the copy and the copy is used for educational, not-for-profit purposes. doi: 10.5210/bsi.v21i0.3873

\title{
The Design of Intentional Communities: A ReCyCled Perspective on Sustainable Neighborhoods
}

\author{
Angela Sanguinetti ${ }^{1}$ \\ University of California-Irvine
}

\begin{abstract}
This article uses Skinner's The Design of Experimental Communities to guide behavior analytic interpretations of non-behavior analytic research on contemporary intentional communities, highlighting ways in which this research substantiates many of Skinner's notions about reinforcement contingencies in a successful community. The article then considers intentional communities in light of more current behavioral theory, such as the notion of reconciling personal and collective contingencies and shifting the balance of resource-intensive, resource-light, and resourcefree reinforcers. This article goes on to suggest one new concept (i.e., macroshaping), along with concepts from outside the field (i.e., deliberative democracy, behavior setting theory) that may be useful in a behavioral approach to the design and analysis of intentional communities.

KEYWORDS: experimental communities, intentional communities, cohousing, cultural analysis, sustainability, Walden Two
\end{abstract}

Over 40 years ago, Skinner (1968) outlined how the science of behavior might contribute to the design and analysis of experimental communities. Twenty years prior he authored Walden Two (Skinner, 1948), a more descriptive but fictional account on the topic. In the 1960s and 70s, dozens of groups tried to create utopic communities based on the ideas in the novel and more generally the science of behavior. Only a few survived, including Twin Oaks in Virginia and East Wind in Missouri. Both have forsaken an explicit Skinnerian orientation, but continue to use economic and governance systems inspired by the novel (i.e., the labor-credit and planner-manager systems).

Twin Oaks and East Wind identify themselves as intentional communities (ICs), a general term that encompasses a variety of types of cooperative living and defines a growing grassroots movement (FIC, 2010). IC can be defined as a

${ }^{1}$ The author may be reached at angelasanguinetti@gmail.com 


\section{SANGUINETTI}

deliberate attempt to realize a common, alternative way of life outside mainstream society (Poldervaart 2001, as cited in Meijering, Huigen, \& Van Hoven, 2007). There are roughly 700 established ICs in the US and over 1,000 currently forming.

Skinner's (1968) definition of experimental community is comparable to the most cited criteria of IC (Meijering, Huigen, \& Van Hoven, 2007; Table 1). The main distinctions between the two include that Skinner discussed experimental communities as societies in microcosm, with a large degree of isolation from mainstream society and a relatively large, heterogeneous population, whereas ICs are, on average, much smaller, can be homogeneous (e.g., senior cohousing-see Durrett, 2009, and student co-ops), and vary in terms of their social, economic, ideological, and geographic withdrawal.

Table 1. Experimental Versus Intentional Community

Experimental Community

(Skinner, 1968)
Intentional Community

(Meijering, Huigen, \& Van Hoven, 2007)
Explicitly designed, or intentional

Ranging from intensely religious to secular

Part of larger governmental structure, or not

Almost always geographically isolated

A certain isolation from tradition

Tests new ways of doing things, an experiment

Variously motivated

Goals often formalized as "values"
No bonds by familial relationship only

Minimum of 3-5 adult members

Members join voluntarily

Geographical and psychological separation from mainstream society

Common ideology

Sharing of (a part of) one's property

Interest of the group prevails over individual interests 


\title{
INTENTIONAL COMMUNITIES
}

\author{
Regarding the research utility of experimental communities, Skinner \\ observed:
}

\begin{abstract}
A community is much more complex than a laboratory experiment in human behavior but much simpler than the large scale enterprises analyzed in political science, economics, and other social disciplines. For this reason it is especially helpful in studying the effects of a social environment on human behavior and, in return, the relevance of that behavior to the maintenance and development of the environment. (1968, p. 64)
\end{abstract}

These theoretical advantages apply to the study of ICs, although perhaps to a lesser degree when an IC is less independent from mainstream culture. The practical value of such research, however, has increased given the growing academic and popular interest in sustainability along with the fact that ICs exemplify many sustainable practices (Brenton, 1998; Ergas, 2010; Fromm, 1991; Kasper, 2008; Kirby, 2003; Marcus \& Dovey, 1991; Margolis \& Entin, 2011; Meltzer, 2005; Moos, Whitfield, Johnson, \& Andrey, 2006; Torres-Antonini, 2001; Williams, 2005a/b, 2008). Behavior analysis is largely absent from research on contemporary, multigenerational ICs; however, the recent special issue of the Behavior Analyst focused on climate change (Heward \& Chance), the establishment of the special interest group Behavior Analysts for Sustainable Societies (BASS), and recent publications in Behavior and Social Issues (Grant, 2010; Newsome \& Alavosius, 2011) suggest that sustainability is of increasing interest to behavior analysts.

The lasting influence of Walden Two on Twin Oaks and East Wind is impressive considering Skinner wrote the novel before many of the principles of behavior analysis were refined through laboratory studies. Behavior analysts now yield an established scientific repertoire that has enormous potential to contribute to the design and analysis of ICs. The goals of this paper are to interpret recent research on ICs in light of Skinner's ideas (per his 1968 paper) and conceptual advances in behavior analysis, as well as to propose concepts from outside the field that may be useful in a behavioral approach to the design and analysis of ICs. First, a brief overview of the context of the current IC movement and types of IC will be provided.

\section{Intentional Community in Context}

Intentional community has a long and rich history, including actualized communities and Utopian visions (e.g., Plato's Republic, $4^{\text {th }}$ Century B.C.; 


\section{SANGUINETTI}

Skinner's Walden Two, 1948). The first ICs on record were those of the Buddhists in the $6^{\text {th }}$ Century B.C. (Kozeny, 2002). The first in America were the Iroquois Confederacy, established by the 1500s, and the Puritan Colonies.

The critical context of the contemporary IC movement includes long-standing criticisms of American suburbia and the single-family detached "dream home." Suburban "sprawl" has been blamed for the breakdown of social institutions (Putnam, 2000), environmental degradation (Johnson, 2001), and lack of physical activity and obesity (Frumkin, Franck, \& Jackson, 2004). The suburban detached single-family dwelling is accused of being unsupportive of current demographics of household composition (Franck \& Ahrentzen, 1991) and reinforcing stereotyped gender roles (Hayden, 1982, 2002).

Planners, urban designers, architects, academics, and policy-makers, increasingly sensitive to these issues, seek to promote greater environmental sustainability, health, equity, sense of community, and sense of place in the built environment with physical design strategies such as New Urbanism (NU), traditional neighborhood development (TND) or neotraditional development (NTD), transit-oriented development (TOD), pedestrian-oriented development (POD), Smart Growth, and compact cities. Features such as high density, narrow streets, short setbacks, front porches, access to public transit, and mixed use zoning are meant to interact synergistically to result in relatively less oil consumption and pollution, more walking, less demand for parking, more lively public spaces, better health, and greater sense of community and place compared to current development patterns. The grassroots IC movement shares goals and physical design strategies with these larger scale top-down, or supply side, approaches. Unlike these other approaches, ICs also experiment with unconventional social contingencies.

\section{Types of Intentional Community}

IC types include ecovillages, cohousing, urban communities, housing cooperatives, conference and retreat communities, rural homesteading communities, spiritual communities, Christian communities, and income-sharing communes (FIC, 2010). An empirically established typology based on the degree of social, geographical, economic, and ideological withdrawal from the mainstream among ICs in Europe, North America, and Oceania yielded four types of communities: religious (most withdrawn), ecological, communal, and practical (most integrated; Meijering, Huigen, \& Van Hoven, 2007). These types are not fixed and exclusive. Cohousing, which might generally be considered a practical type of IC, has become increasingly oriented to ecological responsibility (Durrett 


\section{INTENTIONAL COMMUNITIES}

\& McCamant, 2011) and an ecovillage might be owned as a co-op and use the cohousing model of environmental design.

\section{Cohousing}

Cohousing is the fastest growing type of IC in the US and the subject of much recent IC research, so it will be introduced more thoroughly. There are approximately 134 established cohousing communities in the US and 176 more forming (FIC, 2010; Morris \& Cohen, 2011). Cohousing communities are composed of modest private homes supplemented by shared land and facilities. A common house is typically centrally located, with cooking and dining space for shared meals (of varying frequencies, but generally at least once per week), and may also include a TV room, guest rooms, laundry, children's rooms, work space, and an exercise room. Common land usually includes community gardens and open space; parking is consolidated on the periphery of the community and connected by shared pathways. These design features are referred to as Social Contact Design (SCD; McCamant \& Durrett, 1994). Cohousing is also characterized by participatory design, development, and resident recruitment, as well as participatory and egalitarian community governance and maintenance.

The cohousing model was brought to the US in the 1980s by architects McCamant and Durrett (1994), who adopted the concept from Denmark. George (2006) suggests that the following four characteristics distinguish cohousing from other types of communal living: neighborhood design that features a central meeting place (courtyard, pedestrian street, or internal atrium), a deliberate size that is small enough for members to know each other and large enough to for the group to survive if members occasionally leave (between 20 and 30 units in the US), absence of hierarchy, and separate incomes.

Cohousing is typically new build development, but some communities reuse commercial or industrial buildings or existing housing stock. The latter, housingto-housing adaptive reuse, is known as retrofit cohousing. The most prominent example of retrofit cohousing is N Street Cohousing in Davis, California, which grew within a large suburban single-family housing tract, one house at a time, as residents of adjacent lots tore down the fences between their backyards. For new build cohousing, residents usually lead the development process, but other development models have been used, including partnership (between residents and developer) and speculative (Williams, 2005a). 


\section{SANGUINETTI}

\section{Ecovillages}

Ecovillages are the most ambitious of ICs in terms of aspiring for environmental sustainability. They are the second most common type of IC in the US and the subject of considerable recent research. Gilman and Gilman (1991) define ecovillage by the following characteristics: human-scale (sized so that members can know each other; typically 500 people or less), full-featured (provides major functions to sustain members; shelter, food, sociality, manufacture, commerce, and leisure), harmlessly integrates human activities into the natural world (cyclic use of material resources), supports healthy human development, and can be successfully continued into the indefinite future. Ecovillages can be rural or urban and often use principles of permaculture, cohousing, green construction, alternative energy, and community building practices. According to Kozeny (2002), the ecovillage concept evolved from the cohousing model and first emerged in Europe in the 1980s. There are hundreds of ecovillages worldwide; in the US, there are about 52 established and 127 more in the forming stages (FIC, 2010).

\section{Interpretation of Intentional Community Research a la Skinner (1968)}

Skinner (1968) noted that the design of an experimental community should be driven by two questions. First: What behavior on the part of the members of a community is most likely to contribute to its success? Second: How may that behavior be generated and maintained? These questions guide the extensions of his ideas presented in this paper.

\section{Target Behaviors}

Skinner (1968) noted some "obvious" answers to the first question: "It is important to a community that its members defend it against its enemies, produce the food, shelter, clothing, and other things it needs, and maintain internal order. It is also obviously important that its members teach each other and, particularly, new members, how to behave in necessary ways" (p. 59). He recognized that other behaviors will be important to members (e.g., leisure), depending on the goals of a given community, but advised that "the designer may proceed most effectively by confining himself to behaviors that are demonstrably related to success or survival" (p. 60).

ICs that are somewhat integrated with mainstream society do not aim to be completely self-sufficient, but typically emphasize sustainable practices in the contemporary sense of consuming less and conserving natural resources. For 


\section{INTENTIONAL COMMUNITIES}

example, cohousing communities are so socially and economically enmeshed in mainstream society that they virtually never "fail" in the sense Skinner described regarding experimental communities. Recycling, sharing a lawn mower, composting, and installing solar panels may not be demonstrably related to a cohousing community's survival, but they contribute to the sustainability of society at large. Focusing on sustainable practices in ICs rather than complete self-sufficiency may not be much of a stretch from Skinner's original interest in experimental communities. Skinner's definition of the success of a community, meeting basics needs and the continuation of the community, is strikingly similar to the Brundtland Commission's definition of sustainable development: development that meets the needs of the present without compromising the ability of future generations to meet their own needs (World Commission on Environment and Development, 1987).

\section{Contingencies}

Regarding the second question, how target behaviors may be generated and maintained, Skinner outlined strategies of positive and negative reinforcement (encouraging more of the former, less of the latter). He also described antecedent control strategies, without naming them as such since the concept was still in the forming stages. The following sections outline IC research in terms of these categories.

Positive reinforcement. Skinner (1968) noted the critical role of positive reinforcement for economic functioning, group approval of accepted behavior, and leisure. As previously mentioned, the labor-credit system of Walden Two has proven successful in some ICs (Kuhlmann, 2005). Mulder, Costanza, and Erickson (2005) found that work allocation and reward systems contribute to quality of life in ICs; specifically, "a full $10 \%$ of a resident's happiness is determined by their satisfaction with how fairly a community divides up jobs and acknowledges effort" (p. 18).

Social positive reinforcement via group approval of accepted behavior is supported by findings that cohousing residents benefit from a sense of belonging, self-esteem, social support, living with people with similar interests, and sharing expertise (Brenton, 1998; Marcus \& Dovey, 1991; Williams, 2005a). Skinner's (1968) notion that leisure activities "reinforce the simple behavior of remaining in the community" (p. 64) also fits well with several findings in cohousing research. For example, the frequency and diversity of community activities in cohousing is positively related to the amount of social interaction (Williams, 2005a). In particular, attendance at community meals is positively related to the fulfillment 


\section{SANGUINETTI}

of work responsibilities and negatively related to the number of foreclosures a community has experienced (Margolis \& Entin, 2011).

Negative reinforcement. Skinner (1968) noted that aversive control in the form of sanctions and prohibitive policies should be replaced with ethics and education in an experimental community. There is evidence that this occurs in cohousing in the context of pro-environmental behavior. Meltzer (2005) found that some residents in cohousing were not initially motivated to engage in proenvironmental behaviors, but through interaction and relationship with residents who were so inclined, they learned and became motivated.

Roughly $12.5 \%$ of cohousing communities enforce some work requirements (i.e., have penalties for noncompliance) and 31\% have a system for buying out of work requirements (Margolis \& Entin, 2011). Despite these negative reinforcement contingencies present in a minority of cohousing communities, the finding that attendance at community meals is positively related to fulfillment of work requirements suggests that a community ethic may replace punitive contingencies to some degree in supporting participation in community work. A fair and efficient work system is one of the most cited challenges in cohousing; this is an area that warrants further study, especially by behavior analysts who understand the power of positive reinforcement and the downfalls of aversive control.

Antecedent control. The role of antecedent control is evident in empirical findings regarding pro-environmental behavior and social interaction in ICs. The small scale and cooperative structure of ICs are conducive to resource efficient technologies and practices, such as localizing food systems and collectivizing energy systems (Meltzer, 2005). Specific measures frequently taken in cohousing include composting (96\%), community managed recycling (94\%), low-impact landscaping (84\%), edible landscape and/or permaculture $(77 \%)$, rainwater catchment $(51 \%)$, outdoor clotheslines $(57 \%)$, permanently conserved land through a conservation easement (23\%), community vegetable garden (91\%), community orchard (72\%), raising chickens for egg production (40\%), convenient bike storage areas (67\%), regular carpooling (53\%), and car-sharing (33\%; Margolis \& Entin, 2011).

Cohousing emphasizes environmental design strategies and social structural features that explicitly promote social interaction (McCamant \& Durrett, 1994). Research supports the effectiveness of some of these physical strategies; specifically, social interaction in cohousing is positively related to the quality, accessibility, functionality, and visibility of common spaces, the presence of a privacy gradient, or buffer zone, between private and public spaces, fewer private facilities (e.g., communal laundry in lieu of private washers and dryers) and 


\section{INTENTIONAL COMMUNITIES}

smaller private units (Williams, 2005a). In terms of social antecedent control, communities with stated work requirements function more effectively (Margolis \& Entin, 2011). Member composition can also promote or inhibit social interaction; common goals but diversity in skills and interests are desirable antecedent conditions (Williams, 2005a).

\section{Reconciling Personal, Social, and Ecological Contingencies}

Skinner (1968) noted that the success of an experimental community is the same as the success of all members, individually. Thus, target behaviors will be related to both personal and collective outcomes (e.g., quality of life and ecological sustainability, respectively). Glenn (1986) described the contingencies in Walden Two as reconciling personal and collective interests through such features as a noncompetitive culture and the absence of ceremonial control (i.e., institutionalized social power). These ideas correspond to a pervading theme in IC research that sustainability is promoted through enhanced understanding of the interdependence between the individual, society, and the environment.

What does a sustainable society look and think like?-ecovillages suggest the necessity of a paradigm that facilitates a sense of community wider than the traditionally human one. It means that not only do people have a more accurate understanding of the complex interrelations between themselves and the land, but also that they feel obligated to steward the land that gives them so much. (Kasper, 2008, p. 24)

In his study of Ecovillage at Ithaca (EVI), an ecovillage consisting of four cohousing neighborhoods, Kirby (2003) outlined a more differentiated taxonomy of connections that promote a sustainable lifestyle in ICs: (1) connection with the wild landscape (a spiritual connection with the natural world); (2) connection with community; (3) connection with a cultivated landscape of benign human activity (use of nature); (4) a sense of personal integration (reconnection of separated components of experience); and (5) connection through time, or intergenerational sustainability. These connections are forged through behavioral mechanisms:

Through the adoption of practices at [EVI] that make explicit the connectedness of the individual to the social and ecological worlds both self and environment are being mutually and reciprocally transformed. The development of a new form of social and ecological relations takes place through the everyday lived experience of residents. (Kirby, 2003, p. 332) 


\section{SANGUINETTI}

A basic tenet of behavior analysis is that the more salient a consequence (e.g., in terms of immediacy, magnitude, quality, or probability) the greater control it exerts over behavior. This may be a key mechanism in the relationship between connectedness and sustainable living. The connections Kirby (2003) defined may result from a salient set of contingencies - one directly experienced. For example, the social consequences of one's behavior are salient in close community where interactions are frequent and cooperation essential. Likewise, the effects of one's behavior on the natural environment are more salient when one directly interacts with nature (e.g., when growing food or building shelter). Personal, social, and ecological contingencies are reconciled when the personal consequences of one's behavior are comparable in valence and strength to the consequences of that behavior for the community and the environment.

Skinner (1985) expressed similar notions of alienation and reconnection through direct experience of contingencies relevant to individual success in his theoretical "update from Walden Two," News from Nowhere, 1984:

At the start of his career, Marx got it right. The working classes were suffering more from alienation than from exploitation, as bad as that may have been. ... The worker who is said to feel 'powerless' has nothing to show for his work but his wages, nothing that is his that he has done. The worker who is said to feel 'estranged' from society is spending too much of his day untouched by social contingencies. What it means to say that the worker is 'depersonalized' is a little harder to explain. A person or self is a repertoire of behavior. The repertoire shaped and maintained by daily life is rich and varied. The repertoire shaped and maintained by a factory is small and stale. It does not compose much of a person. ... Walden Two is state ownership without a state. Its members are not employed because there is no employer. They come into direct contact with the world, as people did before there were governments, religions, or industries. They have immediate reasons for behaving - and they behave in ways which not only support their way of life but give them the sense of satisfaction that comes from effective action. (p. 7)

The ideological roots of the idyllic suburban single-family detached dwelling can be traced beyond the alienating forces of the Industrial Revolution - to the Enlightenment philosophy of John Locke (1690a, 1690b), which articulated new relations between self, society, economy, and property (Archer, 2005). Archer (2005) highlights three particularly influential ideological strands: property, pastoralism, and fragmentation. In response to the notion that private ownership of land is a natural and legal right, private property came to function as an 
"articulation of the autonomous, politically potent self" (p. 293). Pastoralism added the requirement of ample space between private detached dwellings, often a nonproductive landscape for leisure pursuits, to protect the individual and nuclear family from the encroachment of outside influences since creating one's identity became an individual responsibility. Spatial segregation of the domestic realm and the public realm further insulated the individual and nuclear family, separating home life from work and other public experiences.

These ideas immigrated with the first English settlers to America, where the privately owned, single-family detached dwelling, already an "emblem of liberation from economic and political bondage" (Archer, 2005, p. 294), had special relevance, land was abundant, and individualism reached a whole new level. This dominant ideology participated in a complex web of forces, including trends in communication, transportation, and trade, with which development patterns in the US have reciprocally evolved. The widespread adoption of the car in the early part the twentieth century, the revolutionary technological advancements in the latter half, and continuing trends toward economic and cultural globalization have enabled greater dispersion of the population relative to previous settlement forms. Private homeownership in suburbia was encouraged by a synergy between federal policy and industrial commercialism post-World War I, interrupted during the Great Depression, then in full force post-World War II (Archer, 2005; Hayden, 2002; Jackson, 1985).

Locke's (1690a, 1690b) concepts of self and identity relied on the "abstraction of the individual from the social fabric of society and the physical fabric of the material world" (Archer, 2005, p. 20). "Locke effectively discounted both the biological and social complexities of the processes according to which consciousness, knowledge, and identity were formed. Not only did this suggest that the self was comparatively autonomous in relation to society but, as a corollary, it atomized people as individuals" (p. 18). As a physical corollary of the hegemonic notions of independence and individualism (i.e., freedom and dignity), it is unsurprising that the suburban form has been associated with isolation, social injustice, and environmental degradation, and that IC, as a countercontrol strategy, would seek to ameliorate these issues by reestablishing connectedness to self, society, and environment, thus reconciling personal, social, and ecological contingencies.

\section{Shaping a Sustainable Society}

Grant (2010) describes the path to sustainability as involving a transition from resource-intensive reinforcers to resource-free and resource-light reinforcers, along with the development of attendant consumption skills. He offers Walden 


\section{SANGUINETTI}

Two (Skinner, 1948) and bohemian communities as exemplars of cultural practices that encourage relative increases in resource-free and resource-light intellectual, artistic, and literary reinforcers and decreases in resource-intensive material consumption. In addition to these more complex cultural reinforcers, ICs exemplify increases in resource-free and resource-light social and natural reinforcers (i.e., those contacted through interaction with the natural environment), which also leads to decreases in material consumption (and may help reconcile personal and collective contingencies). For example, a survey comparing ICs to traditional development found that social capital is higher in ICs and substitutes for income and built capital, allowing for higher quality of life with less material throughput (although this may be due to a self-selection bias; Mulder, Costanza, \& Erickson, 2005).

Grant (2010) advises that "achieving sustainability hinges on how effectively advocates can portray an attractive future based on stable resource consumption and highlight existing subcultural practices that, if properly scaled, can form the basis of such a future" (p. 9-10). Compared to other IC types, cohousing is the most congruent with dominant cultural norms and values and therefore easier to portray as attractive to the mainstream. In fact, Williams (2008) predicts that cohousing will become a mainstream option in the US in the near future.

The benefits, in terms of sustainability, associated with ICs may not be as extreme in cohousing as in communities more ideologically, economically, and socially withdrawn from mainstream culture. For example, cohousing communities are typically much less economically independent than communes and ecovillages, which typically also have a lighter ecological impact. However, if cohousing is adopted in the mainstream, the potential for large-scale impact may be greater than can be achieved by a handful of more radical ICs. As Mattaini (1991) suggested, "perhaps the gap between the current sociocultural situation and that of Walden Two is too large a leap all at once" (p. 53) and a more effective approach might be one involving successive approximations of Skinner's vision.

Although cohousing is the IC type nearest the mainstream, forming or joining a cohousing community is still a big step. This initial action may be most crucial - a behavioral cusp (Rosales-Ruiz \& Baer, 1997) whereby individuals first contact particular resource-free and resource-light reinforcers. Founding or joining an IC also involves complex and effortful behavior. For these reasons, developmental contingencies that involve a shaping procedure might be helpful in promoting ICs as one means of transitioning from resource-intensive to resourcelight reinforcers. 


\section{INTENTIONAL COMMUNITIES}

Shaping processes are implied in research on the diffusion of cohousing (Williams, 2008). These processes have been occurring without contrived contingencies, in a more organic evolution; therefore, they suggest potentially successful shaping strategies. Williams' (2008) research indicates that cohousing adoptions are promoted through bounded normative influence, whereby social connections between cohousers and neighbors create a norm in the proximate geographical surroundings of a community resulting in the gradual growth of existing communities, and that grass-roots processes, including retrofit cohousing, "word-of-mouth" advocacy, and opportunities to "try-before-you-buy-in" (p. 286) have potential to be the greatest impetus of forthcoming cohousing adoptions. The latter two practices suggest shaping as individuals first see and hear about a nearby cohousing community, become interested, visit, rent a unit, or become an affiliated member (participating in some community activities), then eventually buy in or join. Retrofit cohousing, on the other hand, suggests another approach to shaping - one in which the social practices of a community are shaped by the reinforcement of successive steps towards sustainability.

If such a macroshaping procedure could be imagined on a grand scale to transform dominant settlement forms into efficient, self-sustaining communities by way of successive approximations, it might begin with the practices that constitute cohousing and cohousing-like developments, especially retrofit cohousing. Although cohousing is generally more practically-oriented and not as sustainable as more ecological and communal ICs (e.g., ecovillages and communes, respectively), the cohousing movement in the US has become increasingly oriented to environmental responsibility (Durrett \& McCamant, 2011). This could reflect the general trend beyond the cohousing movement, but could also suggest that sustainable practices continue to evolve in cohousing communities as a function of an experimental culture and resource-light reinforcers that reconcile personal and collective contingencies.

Retrofit cohousing (i.e., adaptive reuse of existing housing stock) is perhaps the smallest step away from the mainstream. Many of the barriers to traditional cohousing do not apply to retrofit cohousing. Retrofit cohousing is more accessible because it is less resource-intensive than new build or retrofit of a different land use, which require more time, energy, expertise, money, and financial risk on the part of prospective residents. Retrofit cohousing is also less resource intensive for the environment; construction materials, energy, and waste are reduced and related financial savings increase opportunities for integrating technologies that mitigate environmental impact (e.g., solar panels, xeriscaping; Strobel, 2006). Developers are not involved in retrofit cohousing, so it does not compete with existing housing supply mechanisms, nor is it affected by path 


\section{SANGUINETTI}

dependencies in the industry, which are some of the main barriers to cohousing in the US (Williams, 2008). Finally, compared to other cohousing models, retrofit cohousing may be most compatible with mainstream values of independence, individualism, privacy, property, and homeownership since the housing stock adapted remains in many ways a physical reflection of these dominate cultural ideals.

The concept of macroshaping, in this context, suggests several things. First, making retrofit cohousing a target behavior system - that is, arranging supportive macrocontingencies (Ulman, 1998), may meet with more success than demanding widespread drastic changes to the built and social environment (e.g., full-featured ecovillages). If a significant number of US citizens adopted cohousing principles and practices in their neighborhoods, the perception of the broader culture might shift in the direction of embracing cohousing and intentional community as a mainstream option. Those adopting the cohousing lifestyle might develop critical repertoires (e.g., connection to nature and community), which in turn might establish the reinforcing value of increasingly sustainable lifestyles. In addition to such progressive, naturally-occurring contingencies and macrocontingencies, educational outreach and policy initiatives could promote progressively more sustainable development patterns.

Significant barriers that remain even for retrofit cohousing include unawareness and ideology. Mainstream society is largely unaware of cohousing (and other types of IC). Upon first introduction, cohousing (and other ICs) may evoke connotations of the "hippie" communes of the 1960s and 70s due to shared properties that are otherwise unfamiliar. The limited diversity in early adopters of cohousing in terms of race, income, education, and political affiliation may reinforce these assumptions; cohousers tend to be white, affluent, well-educated, and very liberal (Poley, 2007; Williams, 2005). Racial and socioeconomic diversity in cohousing is increasing thanks to strategies that improve access, such as retrofit cohousing and the provision of affordable units. There are no apparent explicit attempts to increase diversity in political affiliation and ideology; however, nostalgic reference to traditional neighborhoods and an old-fashioned sense of community (e.g., borrowing a cup of sugar, safe place for children to play freely) is a pervasive marketing point that appeals to conservative values.

Researchers' and advocates' relatively greater focus on pro-environmental and pro-social values in cohousing rather than private values related to personal identity, fulfillment, and self-actualization also hints at stereotyped notions of IC. This focus may need to shift if cohousing is to become competitive with a housing form that has monopolized such personal functions. Misconceptions about ICs may have many roots, including seeds of truth, but they contribute to an 


\section{INTENTIONAL COMMUNITIES}

unnecessarily narrow image that appeals to a particular demographic. Meanwhile, most Americans remain unaware of the variety of lifestyles that can be supported in different types of IC and their compatibility with a wide array of mainstream values, including health, safety, child development, aging in place, financial prudence, and localizing resource dependence.

\section{Opportunities for Interdisciplinary Integration}

It is curious that so few behavior analysts have taken interest in experimental communities, a topic that piqued Skinner's interest at the beginning of his career as a visionary application of the science of behavior and one he revisited throughout his life. The study of the contemporary IC movement is a promising opportunity for behavior analysts interested in expanding our cultural analytic concepts and methodologies. We can also look to relevant research from other disciplines for useful insights and compatible concepts to aid our analyses. In this section, two potential areas of interdisciplinary work will be discussed: one content area and one theoretical direction. This paper has already suggested sustainability as an important area of study in the context of IC; another potentially productive content area is governance.

\section{Governance}

Skinner did not revisit the planner-manager system of governance (Skinner, 1948) in his 1968 paper, but as a particular point of contention it warrants special attention. Although a modified version of the system is still used at East Wind and Twin Oaks, the system failed in other ICs and in many cases was blamed for the dissolution of the community (Kuhlmann, 2005). Wolpert (2005) suggests that the planner-manager system is hierarchical and reflects the patriarchal perspective of Western science, characterized by an undervaluation of relationships and subjective ways of knowing. These criticisms should not detract from the value of a behavior analytic approach to ICs:

What Skinner and his science offered was a means for discovering practices that worked, for instance, how best to design physical, childrearing, and social environments for making people healthy, wealthy, and wise. Skinner's utopian vision was not the practices he described in Walden Two, but how the community arrived at themempirically (Altus \& Morris, 2004, p. 271).

Valuable research by Miller and colleagues (Altus, Welsh, \& Miller, 1991; Feallock \& Miller, 1976; Johnson, Welsh, Miller, \& Altus, 1991; Welsh, Johnson, 


\section{SANGUINETTI}

Miller, Merrill, \& Altus, 1989; Welsh, Miller, \& Altus, 1994) at the Walden Twoinspired student cooperative, Sunflower House, developed and refined community management programs. They addressed problems with a hierarchical system of community governance through an iterative process of empirical evaluation and modification of meeting and work-share programs that were originally dependent on researchers (for running meetings and delivering positive reinforcement for resident work contributions). The Walden Two-inspired community of Los Horcones in Sonora, Mexico, proclaims an egalitarian system of governance developed through ongoing experimentation, called "Personocracy" (Los Horcones), which they describe as equitable and unrestricted access to power, participation, and responsibility. These systems, developed with behavioral principles and methodologies, have a participatory character that resembles the consensus systems utilized in most ICs more than the planner-manager system of Walden Two and may be compatible with recent theories of deliberative democracy.

Deliberative, or expansive, democracy contends that participation in deliberative decision-making, through the democratization of institutions that affect people's daily lives, would result in the discursive reconstruction of selves that are more public-spirited, tolerant, knowledgeable, and insightful about one's own and others' interests (Warren, 1992). This makes sense from a behavior analytic perspective, in terms of verbal communities and reconciling personal and collective contingencies. A democratized institution that affects people's daily lives is, in other words, one that puts people in more direct contact with contingencies that affect their lives. It also constitutes a shared verbal community in which contingencies should support learning how to express one's own interests, understand the interests of others, and define collective interests. The contingencies of deliberative decision-making in ICs likely strengthen certain complex verbal repertoires (e.g., perspective-taking) that are not fostered in more conventional residential environments (see Burton \& Kagan, 1994, for relevant analysis).

The small scale of most ICs is conducive to deliberative, consensus decisionmaking, but it is less practical in larger ICs, such as Skinner envisioned. McCamant and Durrett (1994) noted that newly formed cohousing communities typically make even the most minor decisions by consensus, but management becomes more differentiated as trust develops and members come to recognize each other's skills and motivations. Trust and familiarity may function as motivating operations that decrease the value of negative reinforcers for participation in governance (i.e., fear that other community members will not make the right decisions). Perhaps the planner-manager system would generally 


\section{INTENTIONAL COMMUNITIES}

be more successful after a more participatory initial system (a macroshaping approach).

In ICs, the consensus system is regarded with both fondness and frustration. Cited benefits include enhanced interpersonal skills; cited problems imply inefficiency (Kirby, 2003). Consensus and work-share systems are the most cited challenges in cohousing (Margolis \& Entin, 2011). Behavior analytic research into these issues, such as that conducted at Sunflower House (Altus, Welsh, \& Miller, 1991; Feallock \& Miller, 1976; Johnson, Welsh, Miller, \& Altus, 1991; Welsh, Johnson, Miller, Merrill, \& Altus, 1989; Welsh, Miller, \& Altus, 1994), should be of immense interest to IC members.

\section{Behavior Settings}

Some general answers to Skinner's (1968) guiding questions (What behavior on the part of the members of a community is most likely to contribute to its success? How may that behavior be generated and maintained?), particularly in the context of sustainability, can be extracted from IC research. The first question can be answered loosely as behaviors that promote connection with nature and community, and personal integration. Some general answers to the second question, at the cultural analytic level, include sociopetal design (environmental design that promotes social interaction), institutionalized community activities (e.g., shared meals, social clubs, work days), collaborative management, ecological design, community building practices, and community gardening.

From a behavior analytic perspective, rigorous evidence of the functional relations between particular sustainable practices in ICs and their controlling contingencies needs to be established. Conducting functional analyses and assessments to identify the controlling contingencies of target behaviors among individual members might not be the most efficient approach. Although it is important to understand individual level contingencies, for example those involved when individuals and families join an IC, cultural level analyses may be more relevant to the design of ICs. In fact, cultural analyses are suggested by Skinner's questions (i.e., a focus on the behavior of multiple individuals in a given community). Behavior analysts interested in developing the macrocontingency and metacontingency concepts might find ICs fertile ground for their research; others might adopt and adapt suitable concepts from other disciplines.

Ecological psychology offers concepts and methods for studying behavior patterns among more or less interchangeable members of groups in molar environments. The compatibility of ecological psychology and behavior analysis has been previously recognized (Rogers-Warren \& Warren, 1977; Willems, 


\section{SANGUINETTI}

1974). Barker (1968) articulated the behavior setting as the building block of human settlements and the appropriate unit of analysis in ecological psychology. Analogous to the operant, which is defined in terms of a response class and controlling contingencies, a behavior setting is defined in terms of standing patterns of behavior and a sociophysical context.

Specifically, a behavior setting is an objective transindividual pattern of behavior, occurring within specifiable bounds of time and space, together with the context of this behavior, which includes physical properties (e.g., furniture, temperature), human components (e.g., number of people and their roles), and programs (e.g., meeting agenda; Barker, 1968). The part of the physical milieu that corresponds to the behavior patterns, together referred to as a synomorph (e.g., computer keyboard and typing), is a critical aspect of a behavior setting. In behavior analytic terms, a behavior setting identifies recurrent patterns of behavior and a set of stimuli that functions similarly across members of a given culture (Wicker, 1979).

An ecobehavioral approach to understanding ICs also has practical advantages. According to Williams (2008), the complexity of the cohousing model limits diffusion. An inventory of behavior settings (e.g., common meals, community meetings, parties, community garden, work days) is easier to understand than abstract governance and ownership structures and design guidelines (i.e., consensus decision-making, condominium association, Social Contact Design). Additionally, behavior settings in ICs that promote personal, social, and ecological sustainability may be independently applicable to neighborhoods where a full-featured IC would not be accepted nor achievable.

\section{Conclusions}

Skinner's theories about experimental communities are a worthy part of the legacy of radical behaviorism. Their relevance to issues of sustainability invites a timely renewal of interest among behavior analysts. An interpretive review of the contemporary empirical literature on the comparable phenomenon of IC substantiates Skinner's (1968) early ideas about experimental communities. The IC movement provides potentially fruitful research opportunities for behavior analysts to study sustainable practices and further develop cultural analytic concepts and methodologies. Several provocative, but underdeveloped, concepts were discussed in this paper: reconciling personal and collective contingencies (Glenn, 1986); resource-intensive, resource-light, and resource-free reinforcers (Grant, 2010); and macroshaping. Further development of these concepts may be especially helpful in understanding the value and potential of ICs as a means of moving society in a more sustainable direction. 


\section{INTENTIONAL COMMUNITIES}

\section{References}

Altus, D. E. \& Morris, E. K. (2004). B. F. Skinner's utopian vision: Behind and beyond Walden Two, Contemporary Justice Review, 7(3), 267-286. http://dx.doi.org/10.1080/1028258042000266004

Altus, D. E., Welsh, T. M., \& Miller, L. K. (1991). A technology for program maintenance: Programming key researcher behaviors in a student housing cooperative. Journal of Applied Behavior Analysis, 24, 667-675. http://dx.doi.org/10.1901/jaba.1991.24-667

Archer, J. (2005). Architecture and suburbia: From English villa to American dream house. Minneapolis, MN: University of Minnesota Press.

Barker, R. G. (1968). Ecological psychology: Concepts and methods for studying the environment of human behavior. Stanford, CA: Stanford University Press.

Brenton, M. (1998). We're in charge: Cohousing communities of older people in the Netherlands: Lessons for Britain? Bristol: Policy Press.

Burton, M, \& Kagan, C. (1994). The verbal community and the societal construction of consciousness. Behavior and Social Issues, 4, 87-96. http://dx.doi.org/10.5210/bsi.v4i1.210

Durrett, C. (2009). The senior cohousing handbook: A community approach to independent living (2nd ed.). Gabriola Island, BC, Canada: New Society Publishers.

Durrett, C. \& McCamant, K. (2011). Creating cohousing: Building sustainable communities. Gabriola Island, BC, Canada: New Society Publishers.

Ergas, C. (2010). A model of sustainable living: Collective identity in an urban ecovillage. Organization and Environment, 23, 32-54. http://dx.doi.org/10.1177/1086026609360324

Feallock, R., \& Miller, L. K. (1976). The design and implementation of a worksharing system for experimental group living. Journal of Applied Behavior Analysis, 9, 277-288. http://dx.doi.org/10.1901/jaba.1976.9-277

FIC (Fellowship for Intentional Community) (2010). Communities Directory. A Guide to Intentional Communities and Cooperative Living. Rutledge, MI: FIC.

Franck, K. A. \& Ahrentzen, S. (1989). New households new housing. New York: Van Nostrand Reinhold.

Fromm, D. (1991). Collaborative communities: Cohousing, central living and other forms of housing with shared facilities. New York: Van Nostrand Reinhold.

Frumkin, H., Franck, L. \& Jackson, R. (2004). The public health impacts of sprawl. Washington, DC: Island Press.

Kuhlmann, H. (2005). Living Walden Two: B. F. Skinner's behaviorist utopia and experimental communities. Urbana, IL: University of Illinois Press.

George, V. (2006). [Review of Sustainable community: Learning from the cohousing model, by G. Meltzer]. Community Development Journal, 41(3), 393-398. http://dx.doi.org/10.1093/cdj/bsl015

Gilman, D. \& Gilman, R. (Eds) (1991). Eco-villages and sustainable communities. Langley, WA: The Context Institute.

Glenn, S. S. (1986). Metacontingencies in Walden Two. Behavior Analysis and Social Action, 5, 28.

Grant, L. K. (2010). Sustainability: From excess to aesthetics. Behavior and Social Issues, 19, 545. http://dx.doi.org/10.5210/bsi.v19i0.2789

Hayden, D. (2002). Redesigning the American dream: Gender, housing, and family life (Rev. ed.). New York: W. W. Norton \& Company.

Hayden, D. (1982). The grand domestic revolution. The MIT Press. 


\section{SANGUINETTI}

Jackson, K. T. (1985). Crabgrass frontier: The suburbanization of the United States. New York: Oxford University Press.

Johnson, M. P. (2001). Environmental impacts of urban sprawl: A survey of the literature and proposed research agenda. Environment and Planning $A, 33,717-735$. http://dx.doi.org/10.1068/a3327

Johnson, S. P., Welsh, T. M., Miller, L. K., \& Altus, D. E. (1991). Participatory management: Maintaining staff performance in a university housing cooperative. Journal of Applied Behavior Analysis, 24, 119-127. http://dx.doi.org/10.1901/jaba.1991.24-119

Kasper, D. V. S. (2008). Redefining community in the ecovillage. Human Ecology Review, 15(1): 12-24.

Kirby, A. (2003). Redefining social and environmental relations at the ecovillage at Ithaca: A case study. Journal of Environmental Psychology, 23, 323-332. http://dx.doi.org/10.1016/S0272-4944(03)00025-2

Kozeny, G. (2004). Visions of Utopia Volume I: Experiments in Sustainable Culture [motion picture]. Rutledge, MO: Community Catalyst Project; Fellowship for Intentional Community.

Locke, J. (1690a). Two treatises of government. Oxford: Oxford University Press.

Locke, J. (1690b). An essay concerning human understanding. Oxford: Oxford University Press.

Los Horcones (n.d). Personocracy. Retrieved on June 3, 2009, from http://www.loshorcones.org/organization/personocracy.html.

Marcus, C. \& Dovey, K. (1991). Cohousing: An option for the 1990s. Progressive Architecture, 6, $112-113$.

Margolis, D. \& Entin, D. (2011). Report on survey of cohousing communities 2011. CohoUS, www.cohousing.org.

Mattaini, M. A. (1991). Walden 1.9: Successive approximations. Behavior and Social Issues, 1(2), 53-60. http://dx.doi.org/10.5210/bsi.v1i2.167

McCamant, K. \& Durrett, C. (1994). Cohousing: A contemporary approach to housing ourselves $\left(2^{\text {nd }}\right.$ Ed.). Berkeley, CA: Ten Speed Press.

Meijering, L., Huigen, P., \& Van Hoven, B. (2007). Intentional communities in rural spaces. Tijdschrift voor Economische en Sociale Geografie, 98, 42-52. http://dx.doi.org/10.1111/j.1467-9663.2007.00375.x

Meltzer, G. (2005). Sustainable community: Learning from the cohousing model. Victoria, BC, Canada: Trafford.

Moos, M., Whitfield, J., Johnson, L. C., \& Andrey, J. (2006). Does design matter? The ecological footprint as a planning tool at the local level. Journal of Urban Design, 11(2): 195-224. http://dx.doi.org/10.1080/13574800600644381

Morris, B. \& Cohen, R. (2011). [List of cohousing communities]. Unpublished raw data.

Mulder, K., Costanza, R., \& Erickson, J. (2006). The contribution of built, human, social, and natural capital to quality of life in intentional and unintentional communities. Ecological Economics, 59, 13-23. http://dx.doi.org/10.1016/j.ecolecon.2005.09.021

Newsome, W. D. \& Alavosius, M. P. (2011). Toward the prediction and influence of environmentally relevant behavior: Seeking practical utility in research. Behavior and Social Issues, 20, 44-71. http://dx.doi.org/10.5210/bsi.v20i0.3234

Poley, L. D. (2007). Community and the habits of democratic citizenship: An investigation into civic engagement, social capital and democratic capacity-building in U.S. cohousing neighborhoods. (Unpublished doctoral dissertation). Virginia Polytechnic Institute and State University, Blacksburg, VA.

Putnam, R. D. (2000). Bowling alone: The collapse and revival of American community. New York: Simon and Schuster.

Rogers-Warren, A. \& Warren, S. F. (1977). Ecological perspectives in behavior analysis. Baltimore, MD: University Park Press. 


\section{INTENTIONAL COMMUNITIES}

Rosales-Ruiz, J. \& Baer, D. M. (1997). Behavioral cusps: A developmental and pragmatic concept for behavior analysis. Journal of Applied Behavior Analysis, 30, 533-544. http://dx.doi.org/10.1901/jaba.1997.30-533

Skinner, B. F. (1948). Walden Two. New York: Macmillan Publishing Co., Inc.

Skinner, B. F. (1968). The design of experimental communities. From: Sills, D. L. (Ed.) International encyclopedia of the social sciences, 58-65. New York: Crowell, Collier and Macmillan.

Skinner, B. F. (1985). News from nowhere, 1984. The Behavior Analyst, 8(1), 5-14.

Strobel, H. (2006). Building reuse, cohousing, and the land ethic. Urban Action, 13-18.

Torres-Antonini, M. (2001). Our common house: Using the built environment to develop supportive communities, Ph.D. Thesis, Graduate School University of Florida, unpublished

Ulman, J. D. (1998). Toward a more complete science of human behavior: Behaviorology plus institutional economics. Behavior and Social Issues, 8, 195-217. http://dx.doi.org/10.5210/bsi.v8i2.329

Warren, M. (1992). Democratic theory and self-transformation. American Political Science Review, 86, 8-23. http://dx.doi.org/10.2307/1964012

Welsh, T. M., Johnson, S. P., Miller, L. K., Merrill, M. H., \& Altus, D. E. (1989). A practical procedure for training meeting chairpersons. Journal of Organizational Behavior Management, 10, 151-166. http://dx.doi.org/10.1300/J075v10n01_09

Welsh, T. M., Miller, L. K., \& Altus, D. E. (1994). Programming for survival: A meeting system that survives 8 years later. Journal of Applied Behavior Analysis, 27, 423-433. http://dx.doi.org/10.1901/jaba.1994.27-423

Wicker, A. W. (1979). An introduction to ecological psychology. NY: Cambridge University Press.

Willems, E. P. (1974). Behavioral technology and behavioral ecology. Journal of Applied Behavior Analysis, 7, 151-165. http://dx.doi.org/10.1901/jaba.1974.7-151

Williams, J. (2005a). Sun, surf and sustainability: Comparison of the cohousing experience in California and the UK. International Planning Studies Journal, 10(2).

Williams, J. (2005b). Designing neighbourhoods for social interaction: The case of cohousing. Journal of Urban Design, 10(3).

Williams, J. (2008). Predicting and American future for cohousing. Futures, 40, 268-286. http://dx.doi.org/10.1016/j.futures.2007.08.022

Wolpert, R. S. (2005). A multicultural feminist analysis of Walden Two. The Behavior Analyst Today, 6(3), 186-190.

World Commission on Environment and Development (1987). Our common future. Oxford: Oxford University Press. 